\title{
INSTALACIÓN Y USO DE UN COLCHÓN DE NIEVE PARA LA MONITORIZACIÓN DEL MANTO DE NIEVE, CUENCA EXPERIMENTAL DE IZAS (PIRINEO CENTRAL)
}

\author{
J. I. LÓPEZ MORENO(1), B. ALVERA(1), \\ J. LATRON(2) y S. R. FASSNACHT( ${ }^{(3)}$ \\ (1) Instituto Pirenaico de Ecología, CSIC, \\ Campus de Aula Dei, P.O. Box 202 Zaragoza, 50080, Spain \\ (2) Institute of Environmental Assessment and Water Research (IDAEA-CSIC) \\ Jordi Girona, 18-26, 08034-Barcelona, Spain \\ (3) Watershed Science Program, College of Natural Resources, \\ Colorado State University, Fort Collins, Colorado, USA 80523-1472 \\ Correo electrónico de contacto: nlopez@ipe.csic.es
}

RESUMEN. La densidad del manto de nieve resulta una de las variables hidroclimáticas de montaña más difíciles de medir. Los colchones de nieve (snow pillows) representan la herramienta más utilizada para este fin. A pesar de que su uso es generalizado en zonas de Norte América y Escandinavia, y se cuentan con ejemplos de su uso en otras zonas de montaña, no había sido utilizado hasta el momento en la montaña española. En el año 2005 se instaló un colchón de nieve en la Cuenca Experimental de Izas (Pirineo Central) y desde entonces ha proporcionado información de la evolución de la densidad de nieve y el equivalente del manto de nieve en agua (SWE) durante tres años. Este trabajo revisa la historia del uso de este instrumento, las peculiaridades de su uso y los requisitos a considerar durante su instalación. Además, se presentan los resultados obtenidos durante los tres años disponibles detectando algunas fuentes de incertidumbres y destacando su utilidad para la comprensión del comportamiento hidrológico de zonas de alta montaña

ABSTRACT. Snowpack density is one of the most difficult hydroclimatic variables to be monitored in mountain environments. Snow pillows are a commonly used tool for this purpose. Despite they have been widely used in North America, Scandinavia, and several mountains areas, they had not been installed yet in any Spanish mountain system. In 2005, a snow pillow was installed in Izas Experimental basin (Central Pyrenees). Since then, it has provided information on the evolution of density and snow water equivalent (SWE) for a three years period. This paper reviews the history of the use of snow pillows, specifics of its utilization and considerations to have into account when they are installed. Moreover, results 
obtained during the three monitored years are presented. Several uncertainty sources are detected, and the usefulness for understanding the hydrological behaviour of high mountain environments is highlighted.

Palabras clave: nieve, densidad, equivalente del manto de nieve en agua (SWE), colchón de nieve, Pirineos centrales.

Key words: snow, density, snow water equivalent (SWE), snow pillow, Central Pyrenees.

Enviado el 16 de septiembre de 2009

Aceptado el 4 de diciembre de 2009

\section{Introducción}

La presencia estacional de nieve es una de las principales características de las zonas de montaña de latitudes medias y altas. La cantidad y duración de nieve sobre el suelo condiciona numerosos procesos ecológicos (actividad vegetal y de numerosas comunidades animales) y determina la disponibilidad de agua no sólo de las zonas de montaña sino de la totalidad de las cuencas a las que drenan (Haefner et al. 1997). Así, Barnett et al. (2005) identificó numerosas áreas, fundamentalmente en el hemisferio norte, donde la hidrología está dominada por los procesos de acumulación y fusión de nieve. En el Pirineo, se ha estimado que la fusión de nieve representa un $40 \%$ de los caudales primaverales (López Moreno y García Ruiz, 2004) y determina en gran medida la gestión de los principales embalses que suministran agua para los regadíos del valle del Ebro (López Moreno et al., 2008). Así, una correcta monitorización del manto de nieve resulta de gran utilidad para explicar numerosos procesos ambientales en zonas de montaña, así como para prever las reservas de agua acumuladas durante la estación fría que pasarán a ser disponibles durante el período de fusión. Sin embargo, la dureza de las condiciones climáticas invernales y el accidentado relieve de las zonas de montaña suponen una dificultad importante para una correcta estimación de los recursos nivales.

Las variables más habituales que se consideran del manto de nieve son la superficie cubierta de nieve, su espesor y su densidad. La cubierta nival resulta la variable más sencilla de medir, especialmente en los últimos años cuando se ha generalizado el uso de sensores remotos para este fin. Así, la instalación de cámaras fotográficas automáticas, que registran imágenes periódicamente de una ladera o valle y posteriormente pueden ser integradas en un Sistema de Información Geográfico (SIG), está siendo utilizado con frecuencia para el análisis de la evolución de la cubierta de nieve a escalas de detalle (unos pocos kilómetros cuadrados como máximo). Para escalas de trabajo más amplias se utilizan habitualmente imágenes de satélite. La disponibilidad de imágenes desde finales de los años 70, ha permitido analizar la evolución de la cubierta de nieve a escalas hemisféricas (Brown, 1999). Actualmente existe una elevada disponibilidad de imágenes satélite a distintas resoluciones espaciales y temporales que pueden ser utilizadas para este fin. Un ejemplo serían las imágenes MODIS que desde el año 2002 proporcionan imagen diaria de la cubierta nival global a una resolución de 500 metros (Seidel y Martinec, 2004). Mucho más difícil resulta la medición del espesor y, sobre todo, la densidad del manto de 
nieve. Excepto el uso de ciertos sensores instalados en satélites o aerotransportados (atenuación de rayos gamma, uso de microondas o radar), cuya aplicación es generalmente muy costosa y con diversas incertidumbres en áreas topográficamente complejas (Chang et al., 2000), la realización de mediciones manuales o el uso de estaciones nivometeorológicas resultan la única alternativa. La realización de mediciones manuales es a día de hoy una fuente de información fundamental para estudios nivológicos. Estos consisten en la medición directa del espesor y en la obtención y pesado de una muestra completa del manto de nieve para estimar su densidad. De este modo se han realizado estudios sobre la distribución espacial del SWE y su relación con el momento de fusión (Anderton et al., 2002 y 2004). El resultado de una campaña de medición resulta en la obtención de un número elevado de mediciones de espesor y un número mucho menor de estimaciones de densidad para un área relativamente reducida y a una baja resolución temporal. La posibilidad de contar con información a elevada resolución temporal sólo es posible mediante la instalación de estaciones nivometeorológicas. Éstas han evolucionado notablemente en las últimas décadas, siendo mucho más robustas para soportar las adversidades climáticas, y con mayor capacidad para almacenar información a elevada resolución temporal. Además, la información puede ser recibida a tiempo real, mejorando las posibilidades de monitorización y permitiendo detectar cualquier anomalía en el funcionamiento de un sensor, minimizando la existencia de lagunas temporales en los registros (Sorteberg et al., 2001). En las estaciones nivometeorológicas la estimación del espesor de nieve se realiza normalmente mediante sensores de ultrasonidos, proporcionando una estimación precisa de la variación entre la distancia del sensor y la superficie (suelo o nieve). Mucho más compleja es la estimación de la densidad. Siendo que esta variable informa del contenido real de agua en forma de nieve (SWE, snow water equivalent), resulta fundamental en estudios hidrológicos. De los distintos sensores existentes, los colchones de nieve son el instrumento más utilizado en las últimas décadas para la estimación de densidad (Singh y Singh 2001). Sin embargo, lo complejo de su instalación y en gran medida el desconocimiento de sus posibilidades han llevado a que su uso haya sido muy limitado en muchos sistemas montañosos.

En el año 2005 se instaló un colchón de nieve en la Cuenca Experimental de Izas (2.065 m s.n.m., Alto Valle del Gállego, Pirineo central español). En este trabajo se presenta una introducción a las características e historia de uso de este instrumento, se explica el proceso de instalación en la Cuenca de Izas y se presentan algunos datos que se han obtenido durante los años que ha estado en funcionamiento.

\section{Características de los colchones de nieve e historia de su utilización}

Un colchón de nieve se basa en un recipiente, normalmente de nylon, PVC, goma, neopreno o incluso metal, que contiene un líquido anticongelante y se encuentra conectado a una válvula de presión. Así, la nieve que se acumula sobre el colchón hace que el líquido incremente su presión sobre la válvula pudiéndose derivar el peso de la nieve acumulada. Si se dispone de información del espesor del manto de nieve puede estimarse la densidad de la nieve y, por tanto su contenido en agua. Las dimensiones de los col- 
chones de nieve varían según el espesor de nieve que se puede esperar en la zona de medición. Los primeros experimentos se realizaron con colchones circulares de 2 y 4 metros de diámetro (Penton y Robertson, 1967), actualmente también son frecuentes de forma octogonal o cuadrada y de menor superficie, pues se asume la dificultad de su transporte en zonas de Alta montaña (Singh y Singh, 2001).

Los primeros colchones de nieve fueron instalados en Estados Unidos en el Año 1961, y rápidamente su uso se extendió al ser incorporado como un sensor más de las estaciones pertenecientes a la red SNOTEL (SNOwpack TELemetry). A mediados de los años treinta, la Natural Resources Conservation Service (NRCS) monitorizó una serie de puntos de costa oeste de los Estados Unidos, llevando a cabo mediciones manuales de densidad cada mes o quince dias. A partir de los sesenta y básicamente a partir de 1970 se instalaron snow pillows siendo la información enviada a centros receptores sin necesidad de satélites o líneas terrestres. Hoy en día la red SNOTEL mantiene y gestiona 731 estaciones (http://www.wcc.nrcs.usda.gov/). Actualmente, también existen redes de monitorización de la nieve, incluyendo el uso de colchones de nieve en países como Canadá (http://www.env.gov.bc.ca/rfc/river_forecast/bulletin.htm) y Noruega (Sorterberg et al., 2001). De una forma más aislada también se han utilizado en otras zonas como por ejemplo Suecia y Finlandia (Seppälä, 2005), Alpes (Strasser, 2008), Reino Unido (Archer, 1995) y Atlas marroquíes (Schulz y De Jong, 2008).

Fruto de la experiencia en su uso, se ha llegado a la conclusión que resulta una herramienta muy adecuada para la medición de la densidad del manto de nieve, si bien se han detectado una serie de problemas que deben ser tenidos en cuenta para minimizarlos o tener precaución en la interpretación de la información que ellos proporcionan. Los más importantes son:

- La superficie más suave de su superficie en contraste con la rugosidad del entorno puede hacer que el viento se lleve la nieve recién caída de su superficie. Por ello, algunos autores cubren la superficie con una fina capa de tierra y vegetación para simular las características del terreno en que se ubica (Archer, 1995).

- El calor acumulado en el líquido que rellena el colchón de nieve, puede afectar a la fusión del manto de nieve sobre su superficie, especialmente durante el comienzo del período de acumulación.

- La superficie del colchón de nieve puede poseer un albedo distinto a la superficie que lo rodea, acentuando la fusión por radiación.

- Contrastes térmicos, incluyendo ciclos día-noche, pueden inducir cambios volumétricos en el líquido que rellena el colchón causando pequeñas oscilaciones en la señal de presión.

- Si el colchón se coloca en una posición excesivamente plana, puede dificultarse el drenaje del agua que acumulada al manto de nieve incrementándose la densidad de forma artificial.

- El sensor puede presentar problemas para medir mantos de nieve someros. 


\section{Instalación del colchón de nieve en la cuenca experimental de Izas}

En octubre de 2005 se procedió a la instalación de un colchón de nieve en la cuenca experimental de Izas. Dicha cuenca, comenzó a monitorizarse en 1986 y desde entonces se ha recogido información climática, de espesor de nieve y de caudal. La cuenca se sitúa en el valle del Gállego y se abarca un rango altitudinal entre 2060 y 2280 m s.n.m. Cubre una superficie de 33 hectáreas y representa un ambiente de pastos subalpinos y alpinos. Se consideró que la instalación de un colchón de nieve permitiría comprender mejor las relaciones entre evolución del manto de nieve, clima y caudal que sucede en su superficie.

El colchón de nieve posee unas dimensiones de $2.25 \mathrm{~m}^{2}$ (marca Sommer, con sonda de presión USH-8). Está construido de PVC y se rellena con 400 litros de líquido siendo éste una mezcla a iguales proporciones de agua y etilenglicol para evitar su congelación a bajas temperaturas. Se debe asentar sobre una base regular y a ser posible arenosa para facilitar un asentamiento perfecto colchón. La imposibilidad de alcanzar la cuenca mediante transporte terrestre obligó a desplazar los 200 litros de etilenglicol y los 300 $\mathrm{kg}$ de arena, haciendo necesario el uso de un helicóptero.

El colchón de nieve se instaló junto a la torre meteorológica (foto 1), de tal forma que el sensor de altura de nieve (ultrasonidos Campbell SR 50) mide exactamente sobre la superficie de la que se está calculando el peso del manto de nieve. En ese lugar se preparó la superficie donde asentar el colchón (foto 2), teniendo en cuenta las siguientes consideraciones (Kerr, 1976):

- La parte más elevada del colchón debe quedar exactamente al nivel del suelo.

- La válvula debe quedar en una zona bien aislada para evitar oscilaciones diurnas de presión.

- El colchón debe llenarse completamente para evitar la formación de burbujas de aire.

- Todas las costuras deben quedar bien selladas para evitar cualquier pérdida de líquido.

Una vez en funcionamiento, debe tomarse una serie de mediciones manuales de la densidad del manto de nieve, así como compararlo periódicamente con otro tipo de mediciones de precipitación para garantizar que éste funciona correctamente y disponer de una estimación de incertidumbre en nuestros datos. Igualmente debe recalibrarse anualmente estableciendo la relación entre peso sobre el colchón y señal recibida por la válvula de presión. 


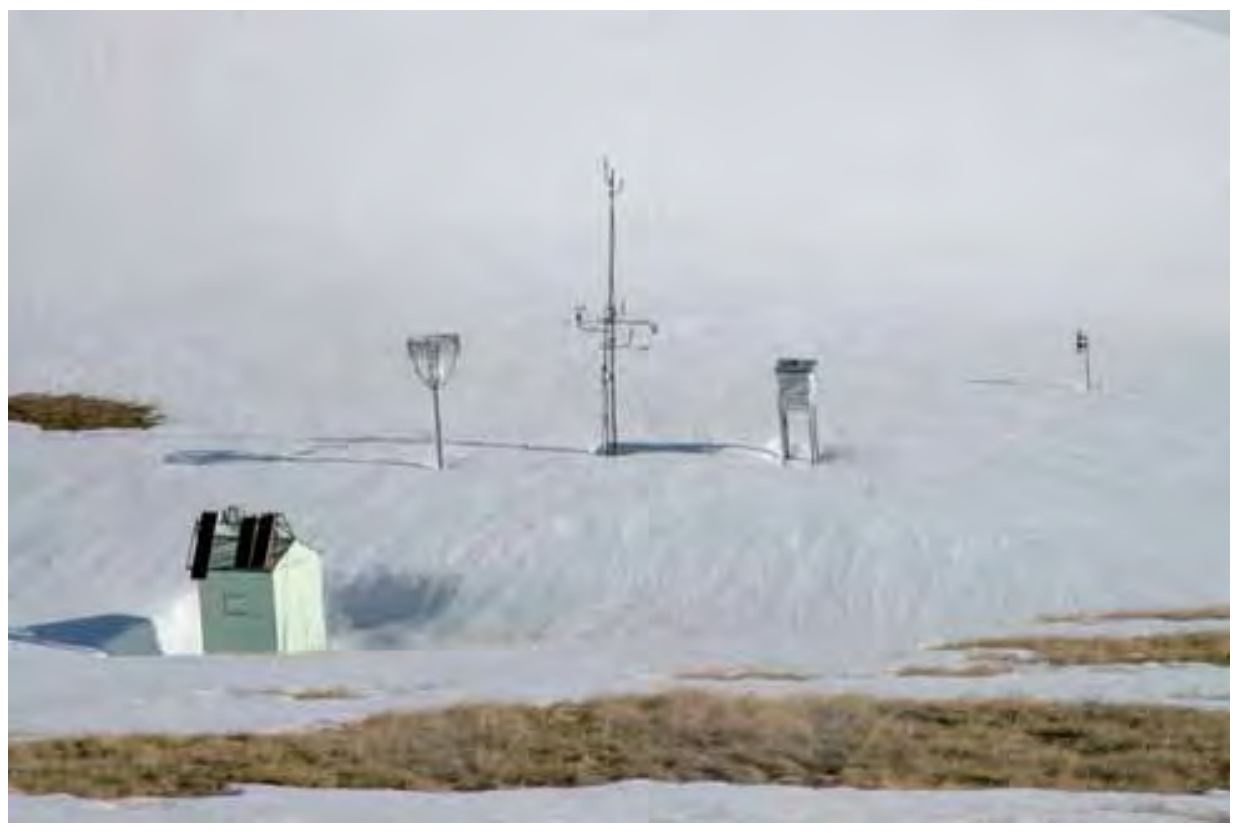

Foto 1. Lugar donde se encuentra instalado el colchón de nieve.

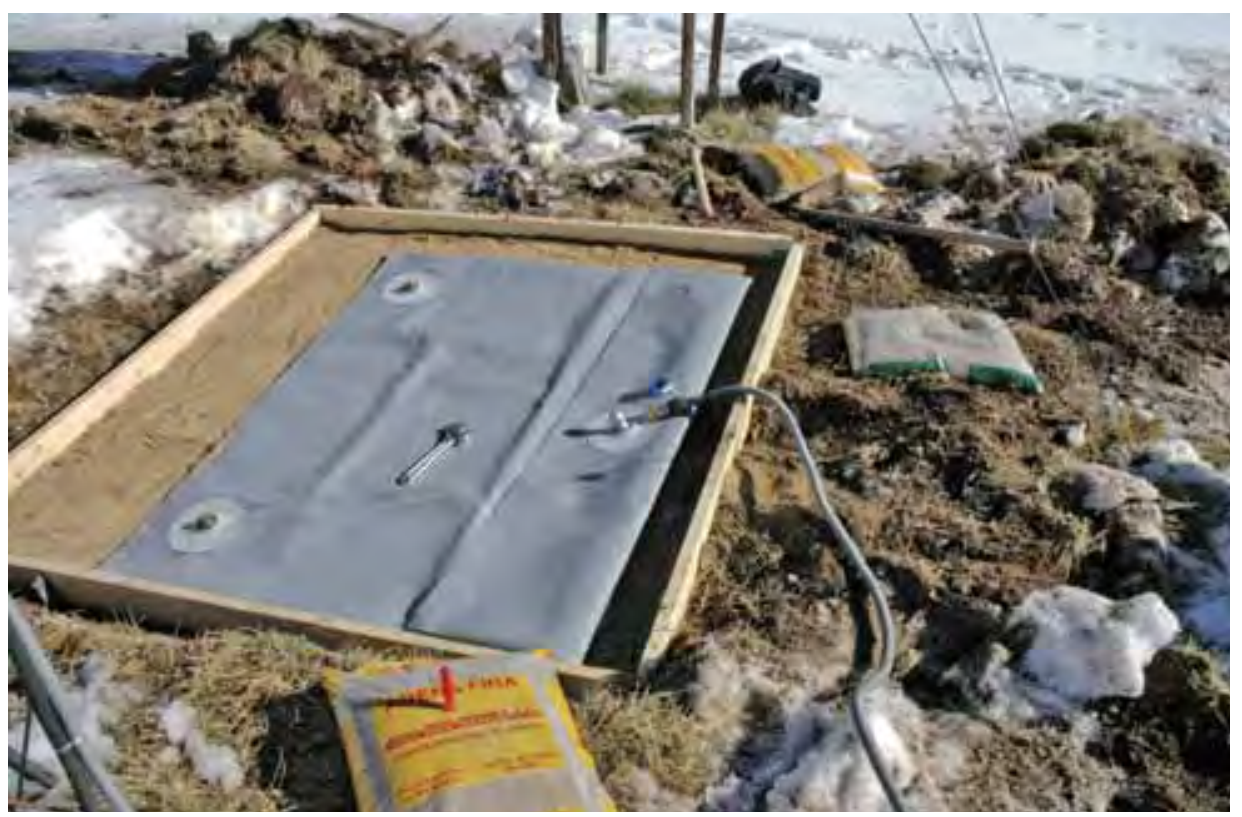

Foto 2. Detalle de la instalación del colchón de nieve. 


\section{Resultados}

La Figura 1 muestra la evolución del espesor de nieve, el equivalente en agua del manto de nieve (SWE) y la temperatura del aire durante las temporadas nivológicas 2005/06, 2006/07 y 2008/09. Una avería en el sensor de presión impidió disponer de información fiable de la temporada 2007/08. Durante febrero de 2009, los paneles solares que alimentan la estación quedaron cubiertos por el manto de nieve durante aproximadamente 3 semanas, período del que se carece de información, pero se estima que el espesor de nieve excedió claramente los $200 \mathrm{~cm}$. Los tres años de los que se disponen datos evidencian la importante variabilidad que muestra el clima, y por tanto el manto de nieve, en la zona de estudio. Así los años 2005/06 y 2008/09 muestran acumulaciones de nieve importantes, en particular en 2009, desde mediados de noviembre hasta finales de mayo. En ambos años, la temperatura media diaria tiende a permanecer por debajo de los $0^{\circ} \mathrm{C}$, ocurriendo muy pocos eventos de fusión durante los meses de invierno. En cambio el año 2006-2007, se caracterizó por una precipitación muy escasa y temperaturas más altas. Dichas condiciones hicieron que el espesor de nieve apenas excediera los $50 \mathrm{~cm}$ de espesor hasta finales del mes de marzo, cuando tres nevadas consecutivas acumularon casi $150 \mathrm{~cm}$ de espesor. De hecho, hay dos momentos en febrero y marzo en el que la nieve llega a desaparecer completamente del observatorio, un hecho que a más de $2.000 \mathrm{~m}$ s.n.m. puede considerarse excepcional.

La evolución del contenido de agua total (sólida y líquida) del manto de nieve (SWE) confirma las condiciones climáticas y nivológicas tan distintas de los tres años analizados. En general las series de SWE muestran una menor variabilidad de alta frecuencia que las series de espesor, ya que muchas de las oscilaciones de espesor de nieve no se reflejan en las series de SWE. Así, la pérdida de espesor no afecta al contenido de agua pues está reflejando la ocurrencia de procesos de densificación del manto de nieve por compactación (puede verse que sucede, en ocasiones, en períodos que la temperatura no excede los $0^{\circ} \mathrm{C}$ ) o incremento del contenido de agua en estado líquido del manto de nieve (en períodos que la temperatura claramente excede los $0^{\circ} \mathrm{C}$, desciende el espesor pero se mantiene el constante el SWE).

La Figura 1 muestra también que la diferencia entre espesor y SWE varía notablemente entre los tres años analizados y también a lo largo de cada temporada de nieve. En general, desde noviembre hasta finales de febrero existe una diferencia muy marcada entre las curvas de espesor y SWE, evidenciando que durante ese período el manto de nieve permanece con una densidad muy baja, debido a las bajas temperaturas que evitan una transformación intensa del manto de nieve. La Figura 2 muestra el promedio mensual de densidad y espesor de nieve correspondiente a los tres años de medición. Puede observarse que, en general, la densidad de nieve durante los primeros meses de las tres temporadas la densidad de nieve permanece muy baja (200-300 $\mathrm{kg} \mathrm{m}^{-3}$ ), incrementándose progresivamente al paso del tiempo. Sin embargo, el ritmo de transformación del manto de nieve varía mucho de un año para otro (p. ej. comparando 2005/06 y 2008/09). El año 2006/07 muestra un comportamiento muy distinto a los otros dos años de mayor innivación y temperaturas más frias. En este caso, la frecuente existencia de temperaturas por encima de $\operatorname{los} 0^{\circ} \mathrm{C}$ durante toda la temporada hace que la transforma- 


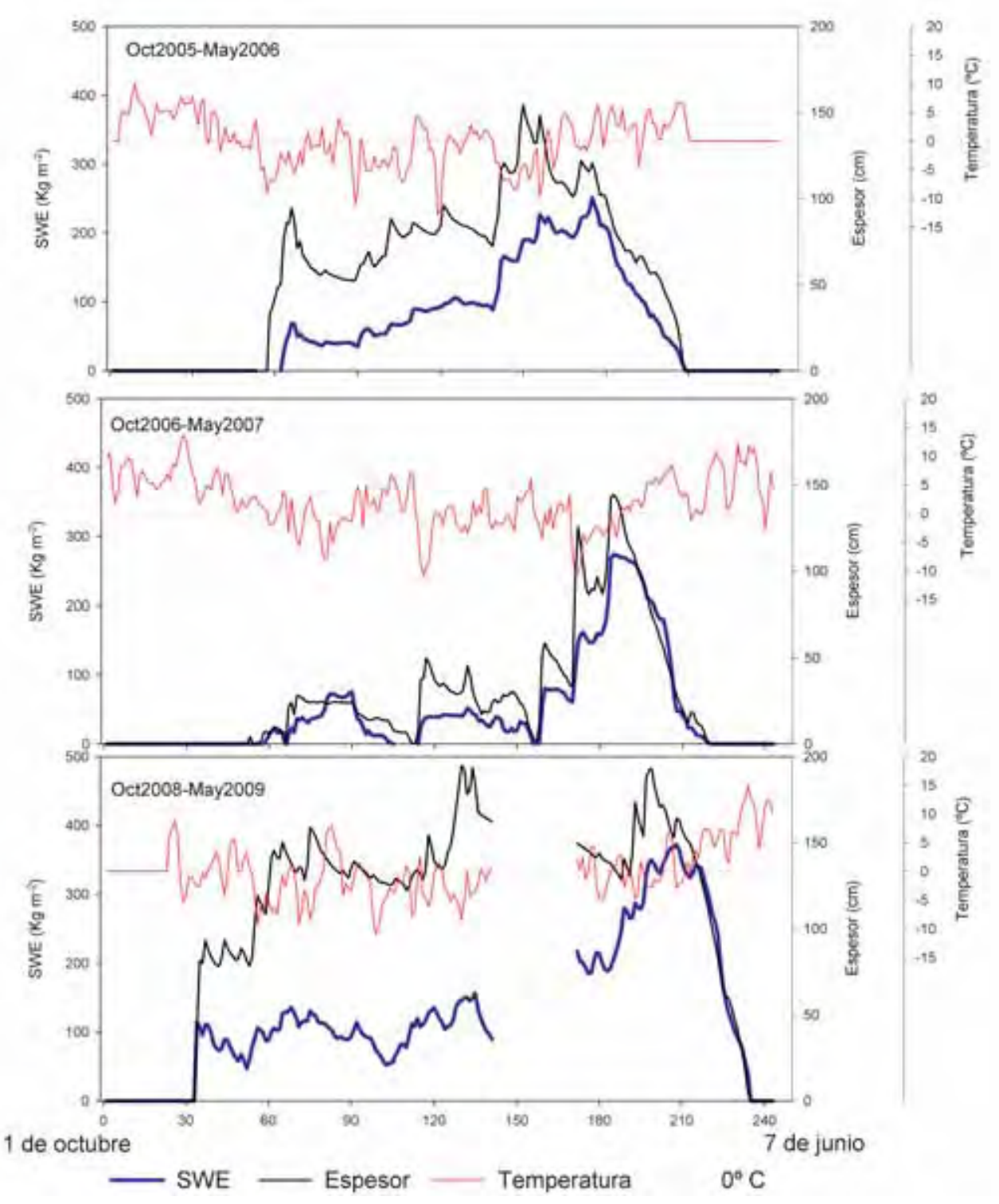

Figura 1. Evolución del espesor de nieve, el equivalente en agua del manto de nieve (SWE) y la temperatura durante las temporadas nivológicas 2005/06, 2006/07 y 2008/09. 


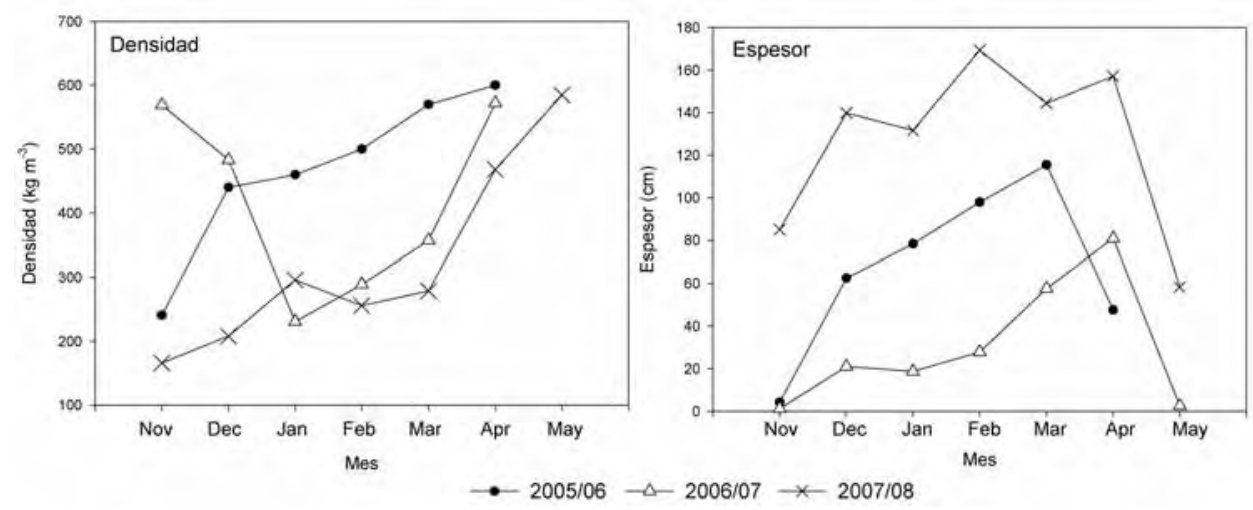

Figura 2. Promedio mensual de la densidad (A) y espesor de nieve (B) correspondiente a los tres años de medición.

ción del manto de nieve se produzca desde el comienzo del invierno, mostrando valores de densidad de la misma magnitud que se observa en los otros dos años durante los meses de primavera. Además, la Figura 1 evidencia que el sensor del colchón de nieve puede ofrecer problemas en situaciones de manto de nieve muy somero. Así, en un momento de fusión total que sucede en febrero, el sensor de SWE indica que el manto de nieve ha desaparecido completamente, mientras el sensor de altura indica un espesor de más de $10 \mathrm{~cm}$. Los días previos a este dato, se produce un descenso muy importante de SWE, que no queda explicado por los cambios de espesor (en torno a $30 \mathrm{~cm}$ ). Este comportamiento irregular del sensor en condiciones de manto de nieve somero, hace que deba considerarse con prudencia el descenso tan acusado de densidad durante los meses de diciembre y enero (Fig. 2).

En los tres años analizados existe un claro incremento de la densidad del manto de nieve durante los meses de fusión (de marzo a mayo) alcanzando valores de hasta $600 \mathrm{~kg}$ $\mathrm{m}^{-3}$ en los meses de abril y mayo. La Figura 3 muestra en detalle la evolución del espesor del manto de nieve, SWE y temperatura mostrados en la Figura 1, durante el período de fusión de primavera hasta su completa desaparición. Como puede apreciarse en los tres años la temperatura media diaria supera ampliamente los $0^{\circ} \mathrm{C}$. En el año 2006 el período de fusión abarca desde el 28 de febrero hasta el 27 de abril, en 2007 sucede desde 3 de abril hasta el siete de mayo y en 2009 desde el 18 de abril hasta el 24 de mayo. Estas cifras muestran de nuevo la elevada variabilidad interanual que afecta a los procesos nivales en el Pirineo, con diferencias de hasta casi un mes en la duración del manto de nieve. Un elemento común en los tres años analizados es que desde que las temperaturas comienzan a exceder de forma clara $\operatorname{los} 0^{\circ} \mathrm{C}$ y el espesor de nieve inicia su descenso hasta que SW responde de forma clara pasan entre 20 y 30 días. Durante este período, las elevadas temperaturas e intensa radiación produce un intenso metamorfismo, en el que el manto de nieve alcanza progresivamente condiciones isotermas (próximas a los $0^{\circ} \mathrm{C}$ ) en todo el perfil y se incrementa notablemente el contenido en agua del agua del manto de nieve (SWE). Una vez alcanzado este punto, toda llegada de energía (temperatura, radiación, etc.) se 


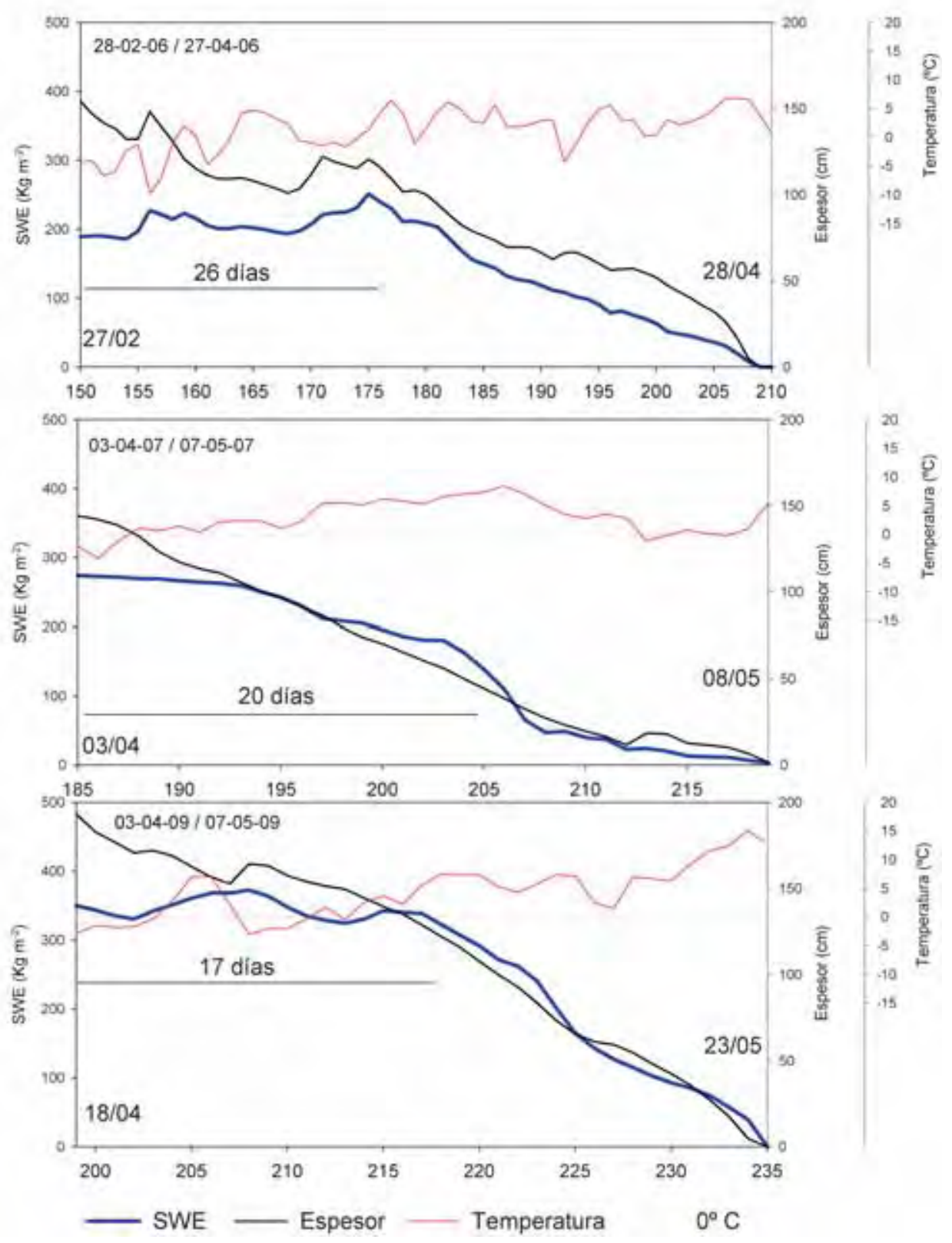

Figura 3. Detalle de la evolución del espesor del manto de nieve, SWE y temperatura durante el período de fusión. Se indican las fechas de comienzo y final del evento de fusión y el período que tarda SWE en responder. 
traduce en fusión del manto de nieve y sólo son necesarios entre 15 y 20 días para que desaparezca completamente el manto de nieve. La Figura 3 también muestra la existencia de descensos en SWE muy bruscos, fundamentalmente en primavera de 2007 y 2009 , que no siempre guarda relación con la pendiente de descenso de espesor de nieve. Algunos trabajos (Pomeroy y Brun, 1999) indican que se trata de momentos en el que el manto de nieve acumula elevadas cantidades de agua en estado líquido, que son drenadas de forma muy rápida fuera del colchón de nieve.

\section{Conclusiones}

Durante los tres años de medición del espesor y densidad de nieve en la Cuenca Experimental de Izás se ha podido comprobar que el colchón de nieve representa una herramienta muy útil para la monitorización en continuo de la densidad y SWE del manto de nieve. Como desventajas debería citarse lo relativamente complejo de su instalación y mantenimiento (necesidad de recalibrar anualmente, problemas técnicos con la válvula de presión, etc.) y la incertidumbre asociada a períodos de espesores de nieve poco profundos o un drenaje del agua contenida en el manto de nieve de forma irregular.

Los resultados han mostrado que los procesos de acumulación y fusión de nieve en el Pirineo presenta una elevada irregularidad interanual. Dicha irregularidad se refleja en la contrastada evolución de la densidad a lo largo del año, que si bien tiende a mostrar una evolución ascendente a lo largo de la temporada, presenta valores muy distintos a lo largo de cada año. Además, se ha detectado la existencia de un retardo entre el comienzo de la disminución del espesor y el SWE de hasta un mes, período en el que el manto de nieve está sujeto a un profundo metamorfismo. Por tanto, no se puede asociar de forma directa descensos en el espesor del manto de nieve de una cuenca determinada con el comienzo de la ocurrencia de caudales de fusión. Sin embargo, una vez el manto de nieve alcanza condiciones isotermas, la reducción en SWE sucede de una forma muy rápida. Este resultado sugiere la necesidad de monitorizar, simular y comprender los cambios en las características físicas del manto de nieve, incluyendo su densidad, pues resulta un elemento clave para comprender la respuesta hidrológica de las cuencas de montaña.

\section{Agradecimientos}

Este trabajo ha sido financiado con los proyectos CGL2008-01189/BTE, CGL2006-11619/HID y CGL2008-1083/CLI, financiados por la Comisión Española de Ciencia y Tecnología y FEDER, y "Las sequías climáticas en la cuenca del Ebro y su respuesta hidrológica" y "La nieve en el Pirineo aragonés: Distribución espacial y su respuesta a las condiciones climáticas", financiados por la Obra Social de La Caixa y el Gobierno de Aragón, y el Programa de grupos de investigación consolidados financiados por el Gobierno de Aragón. Los autores agradecen a Emilio Ubieto su ayuda en la instalación del colchón de nieve y su trabajo en el mantenimiento de la Cuenca Experimental de Izas. 


\section{Referencias bibliográficas}

Anderton, S. P., White, S. M., Alvera, B. (2002). Micro-scale spatial variability and the timing of snow melt runoff in a high mountain catchment. J. Hydrol., 268: 158-176.

Anderton, S. P., White, S. M., Alvera, B. (2004). Evaluation of spatial variability in snow water equivalent for a high mountain catchment. Hydrological Processes, 18 (3): 435-453.

ArChER, D. (1995). The installation and use of a snow pillow to Monitor snow water equivalent.CIWEM, 9: 221-230.

Barnett, T. P., Adam, J. C., Lettenmaier, D. P. (2005). Potential impacts of a warming climate on water availability in snow-dominated regions. Nature, 438: 3.003-309.

Brown, R. D. (1999). Northern hemisphere snow cover variability and change, 19151997. Journal of Climate, 13: 2.339-2.355.

Chang, K. T., LI, Z. (2000). Modelling snow accumulation with a geographic information system. Int. J. Geographical Information Science, 14 (7): 693-707

Haefner, H., Seidel, K., Ehrler, Y. (1997). Applications of snow cover mapping in high mountain regions. Phys. Chem. Earth., 22 (3-4): 275-278.

KERR, W. E. (1976). Snow pillow experiences in a prairie (Alberta) environment. Proceeding of the 1976 Western Snow Conference, pp. 39-47. Calgary, Alberta.

LÓPEZ-Moreno, J. I., García-Ruiz, J. M. (2004). Influence of snow accumulation and snowmelt processes on the distribution of streamflow in the central Spanish Pyrenees. Journal of Hydrological Sciences, 49: 787-802.

López-Moreno, J. I., García-Ruiz, J. M., Beniston, M. (2008). Environmental Change and water management in the Pyrenees. Facts and future perspectives for Mediterranean mountains. Global and Planetary Change, 66 (3-4): 300-312.

Penton, V. E., Robertson, A. C. (1967). Experience with pressure snow pillow as a snow measuring device. Water Resources Research, 3: 405-408.

Pomeroy, J. W., Brun, E. (1999). Physical properties of snow. In: Snow Ecology (Jones, H.G., Pomeroy, J.W., Walker, D.A., Hoham, R., Edrs.). Cambridge. University Press, Cambridge, UK.

SEPpÄLÄ, M. (2005). The Physical Geography of Fennoescandinavia. Ed. Oxford University Press, 419 pp., UK.

Seidel, K., Martinec, J. (2004). Remote Sensing in Snow Hydrology. Springer, 150 pp., Cichester.

Schulz, O., De Jong, C. (2008). Snowmelt and sublimation: field experiments and modelling in the high Atlas mountains of Morocco. Hydrology and Earth System Sciences, 8 (6): 1.076-1.089. 
Sorteberg, H. K., Engeset, R. V., Udnaes, H. C. (2001). A national network for snow monitoring in Norway: Snow pillow verification using observations and models. Physiscs and Chemestry of the Earth C, 26 (10-12): 723-729.

Singh, P., Singh, V. P. (2001). Snow and glacier hydrology. Ed. Kluwer, 742 pp., Dordrecht.

Strasser, U. (2008). Snow loads in a changing climate: new risks?. Natural hazards and Earth System Science, 8: 1-8. 